\title{
The Role of Sociocultural Beliefs in Sustainable Resource Management: A Case Study of Traditional Water Harvesting Systems in Kathmandu Valley, Nepal
}

\section{MIRA TRIPATHI, KENNETH F. D. HUGHEY AND HAMISH G. RENNIE}

Faculty of Environment, Society and Design, Lincoln University, Lincoln, New Zealand

Email: mira.tripathi@lincolnuni.ac.nz

ABSTRACT This case study helps to develop a better overall understanding of the roles and need for managing traditional water management technologies and to focus greater attention towards preserving them. The unique traditional stone spouts of the Kathmandu Valley, Nepal, demonstrate human ingenuity in harnessing subsurface flows and are, as well, an example of outstanding social accomplishment in the form of communal collaboration. In addition, in places, some of these spouts are recognised as having significant heritage conservation value and thus contribute, via tourism, to the local and national economy. This study shows the current values of traditional spouts and their connection with social and cultural norms by comparing two spouts in peri-urban heritage areas of the Kathmandu Valley in Nepal. Ultimately, it shows that in the presence of an alternative modern piped water supply system, which is inherently unreliable at times, the absence of an appropriate property right system is leading to the ongoing decline in the state of these traditional spout systems.

\section{KEY MESSAGE}

The basis for developing a simple approach to measuring and understanding the multiple values of traditional water management technologies, and thus for considering how they should be managed in the future, is presented. Readers will learn about the contribution of sociocultural beliefs, thoughts and traditional institutional norms and values to management of traditional water harvesting systems. They will understand the importance of communal ownership and the impact of modern technology in operating these traditional technologies in a sustainable way. Ultimately, there is an argument that modern pipeline systems and traditional spout infrastructure are complementary and thus achieve multiple outcomes.

\section{INTRODUCTION}

Despite Earth's extensive fresh water resources, billions of people in many places still have limited access to basic water services due to unsustainable management practices [I ]. Sustainable water resources management has thus become a key challenge for people in many countries suffering from unreli- able supplies of clean water. To help overcome this challenge, traditional water harvesting and management techniques are still used in many places, including Nepal. However, despite being efficient and cost effective, it seems these traditional methods are either in decline or have been completely abandoned in many countries [2]. Not only does such a loss impact on water supply but it also impacts on cultural values, religious practices and on heritage values (which in places are important for tourism, and thus on economic values) $[3,4]$. In some countries, such as Nepal and Iran, however, resources continue to be invested to sustain water provision via these traditional techniques $[5-7]$. The extent to which such traditional measures may endure modernisation pressures, with a focus on Nepal, is a key driver of this case study, and a question for the sustainable use of fresh water.

\section{CASE EXAMINATION}

Stone spouts were the first hydraulic structure used in Nepal to collect and distribute drinking water. Most stone spouts were built in Kathmandu (176), Lalitpur (6I) and Bhaktapur ( 152 ) districts of Kathmandu Valley (total 389 ) in the fifth to seventh centuries during the Lichhavi dynasties [8-10]. More

Case Studies in the Environment, 2018, pps. I-8. electronic ISSN 2473-95 10. () 2018 by the Regents of the University of California. All rights reserved. Please direct all requests for permission to photocopy or reproduce article content through the University of California Press's Reprints and Permissions web page, www.ucpress.edu/journals.php?p=reprints. DOI: https://doi.org/10.1 $525 /$ cse.201 7.00085 I 
were added until i 829 [I I ]. Shallow aquifers and springs were used as a source of water for stone spouts [5]. The aquifers supplying water to these spouts were recharged not only by precipitation but also by state canals (called royal canals or raj kulo in the local language) through which water was conveyed from the foothills to artificial ponds and infiltrated from ponds to the spouts [5]. State canals, ponds and other water networks were maintained in such a way that stone spouts could supply water with good quality and quantity throughout the year, $24 \mathrm{~h}$ a day [5, I 2]. Many fonts of stone spouts are beautifully constructed with stone and metal crafts in the shape of a crocodile, snake or other animal with the water coming out of the mouth [5, I3].

Despite the age of the traditional infrastructure, some traditional water spouts have remained operational. However, the development of new water supply technologies has brought further traditional construction of such spouts to a standstill [3]. Stone spouts are drying out and disappearing, a feature attributed to rapid population growth, modern pipeline water supply systems, unplanned urban development and haphazard construction of dug wells along their sources [12]. Within the city of Kathmandu, many stone spouts, particularly those within the Bhaktapur Heritage District, have religious, cultural and heritage value, the latter reflected within the World Heritage Status accorded over the area in I 979 [ I 2]. Our research concerned the changing state of these spouts across the range of their values, the drivers affecting such changes, and whether any of the driving forces could or should be harnessed to protect the future of these resources.

Baseline field research determined the state (physical) of stone spouts in Bhaktapur district based on multiple criteria (e.g., rate of spout flow; reliability of flow; degree of development encroachment on the spout and surrounds; degree of change to ornamental features) [3]. Results of this work showed that spouts, surprisingly, in non-heritage areas of the urban and peri-urban environments were typically in a better state than those in equivalent heritage areas [3, I 4 .

Further interview-based research was undertaken into the cultural, religious and other links to the spouts and into the multiple reasons for their general state of decline. The research reported here is based on qualitative and quantitative data collected from interviews with six planners and experts and 18 community members as well as field observations of two stone spouts: Narayan hiti and Sangdaha hiti (hiti means stone spout in the local lan- guage) in the peri-urban heritage (Changunarayan) area of the Bhaktapur District. About $98 \%$ of households in the study area are indigenous Newar, mostly with an agriculture background [i 5$]$. Seven focus group discussions with four to six respondents were also completed to understand the attitudes, feelings and beliefs experienced and the reactions of participants to the subject matter. The same semistructured questionnaire was used for interviews and group discussions.

Narayan hiti has good water flow and retains cultural importance. Conversely, after introduction of a modern pipe-line water supply system, Sangdaha hiti has gradually been destroyed and ultimately descended into debris (Figures I and 2, respectively). The next two sections describe the drivers that are contributing to the maintenance of Narayan hiti and those that have led to the destruction of Sangdaha hiti.

\section{SIGNIFICANCE OF TRADITIONAL NORMS AND} VALUES IN WATER RESOURCES MANAGEMENT

Findings from community member interviews and focus group discussions show that in the areas where Newar indigenous communities and culture predominates, most spouts feature Shiva (God). At the ceremonies where Newars worship their ancestors, their culture permits them only to use spout water.

Narayan hiti, in the Changunarayan area, has special religious significance. Only water from Narayan hiti is allowed to be used at the Changunarayan (God) temple for the purposes of worshipping (this temple is listed in the 1979 UNESCO World Heritage List). There are two stone spouts at one platform at Narayan hiti (Figure I). One (on the right inside, the frame of Figure I and having a good flow of water) was for offering water to the Changunarayan temple; the other (on the left inside, the frame and dry in Figure I) is for public use. The strongly flowing spout formerly provided water to the Changunarayan temple but was locked by the Bhandel (a caste of Newar assigned to carry water for the Changunarayan temple). Around 40 years ago, the other spout at this location completely dried out and the local people broke the priests' shackles and started to use the Changunarayan's spout. Nowadays, the same spout is used for offering water to the Changunarayan temple as well as fulfilling the daily needs of local people.

Narayan hiti was also important to the Newar culture in matters concerning the touching of pigs. If they did 


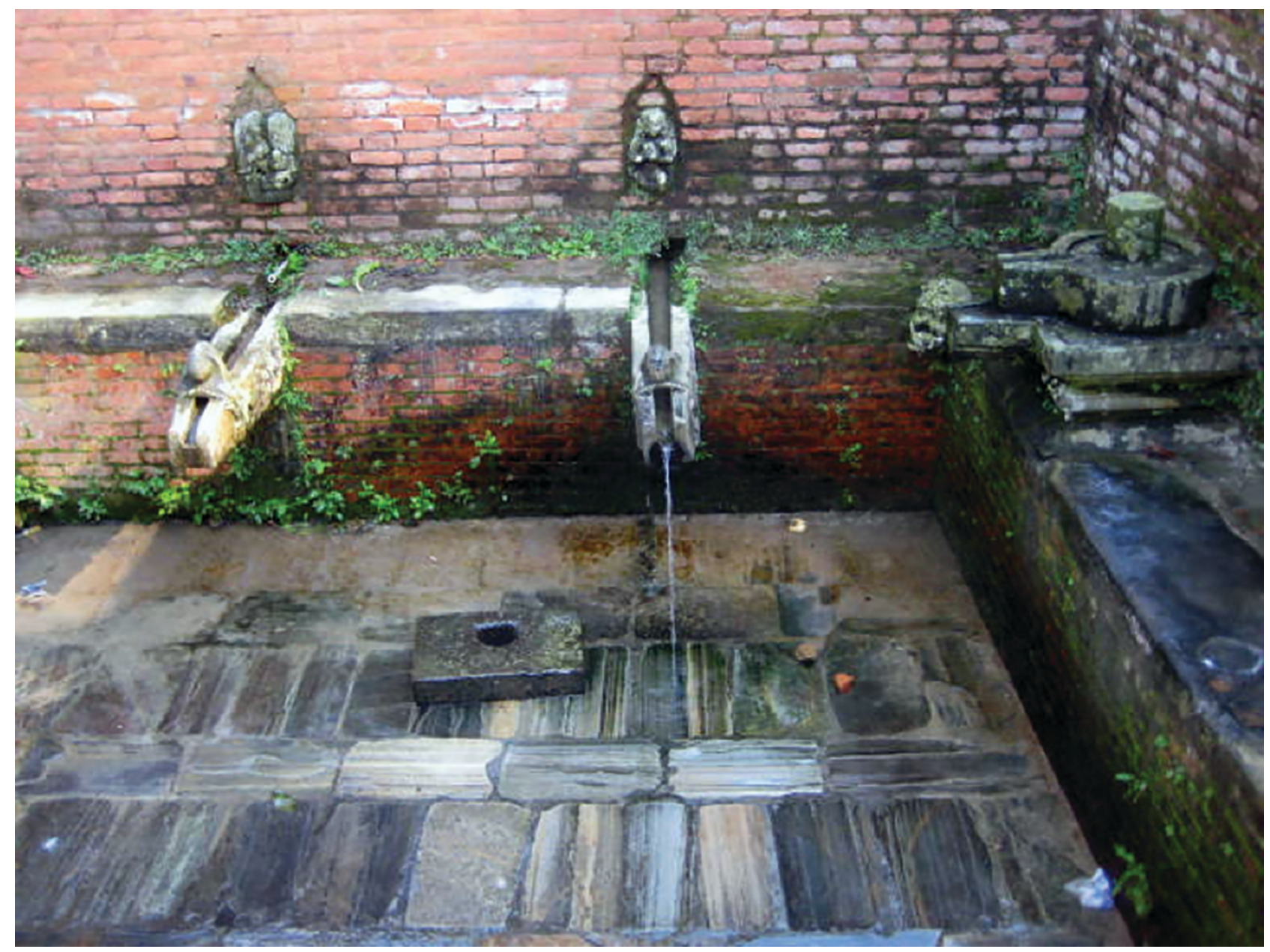

FIGURE 1. Narayan hiti.

come into contact with a pig or pork, they had to shave their head and bath in Narayan hiti to recover their purity. Failure to perform this ritual could lead to a Newar being prevented from entering their dwelling.

Analysis of the perceptions of people living in the periurban heritage area of Bhaktapur shows that traditionally spouts were sustained or managed partially through religious and general belief-driven actions. Individual local people and social groups in the communities were thus motivated to be proactive in cleaning and maintaining spouts. For instance, most old male and female community respondents explained that women going through their monthly period and lower caste people are not allowed to make use of Narayan hiti. As caste was determined based on the activities performed by people, and the lower caste people did the work that was unsanitary (e.g., cleaning toilets, leather works, or field work), this functional demarcation effectively barred lower castes from the spouts. According to respondents, a cultural boundary was created through these rules. Leather items, the innerwear of men and women and footwear are still not allowed to be washed at the spout. Wearing shoes has also been banned on the spout's platform. It is a commonly retained belief that if citizens polluted the water spout, Changunarayan (God) would get annoyed and cause plague and sickness. Even though there might be some sound scientific reasons for such rules, they are couched in the language and context of metaphysical belief systems. These beliefs have a residual benefit in guiding public behaviour in favour of stone spout conservation.

Most respondents, however, had a more utilitarian view of spouts. They stated that when there was no reliable source of water, people built stone spouts. Later, wells were dug, and then pipelines introduced. Thus, fresh and clean water was easily available and largely maintenance free. Slowly people started ignoring spouts. Locals began 


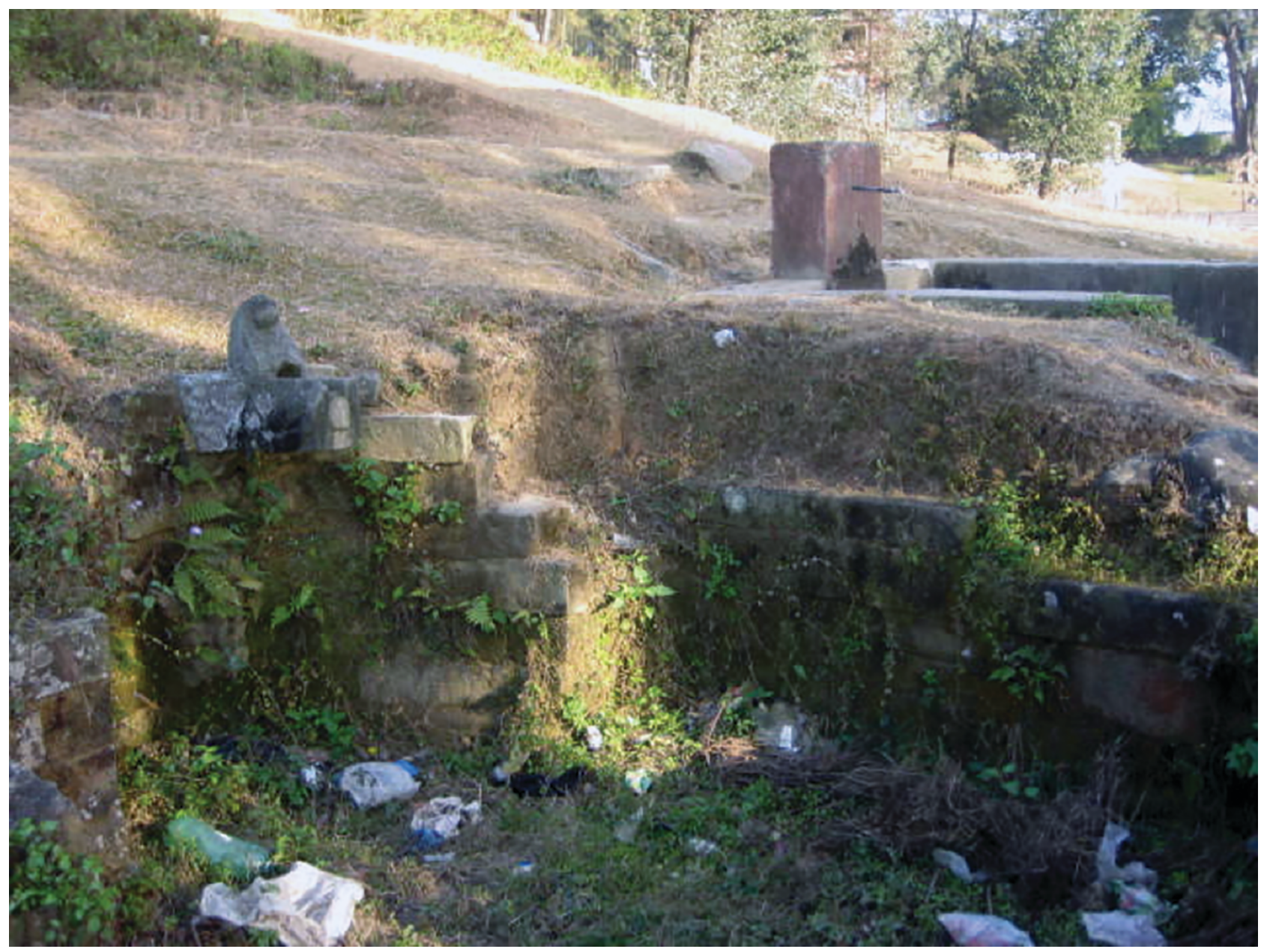

FIGURE 2. Sangdaha hiti: the traditional spout is in the left foreground; the more recent reticulated supply is in the right background.

polluting the spouts, and their decline began. As mentioned earlier, there are two stone spouts at one platform at Narayan hiti (Figure I). One of these spouts has already dried out because of its lack of cultural and related social value attachment, and also because of the presence of a modern pipeline water supply system. The impact of modern systems is illustrated through Sangdaha biti.

\section{MODERN TECHNOLOGY-A CHALLENGE TO}

\section{SUSTAINING TRADITIONAL APPROACHES}

Sangdaha hiti (Figure 2) is now a dysfunctional stone spout, but to understand the reasons for its demise requires an understanding of the complex development pressures and contexts imposed on the spout.

Gradually, with the development of modern water supply systems, the ancient and medieval stone spouts and communal water supply systems, in general, became regarded as less useful than the private and personal water taps of houses and subsequently have been neglected in Nepal [7]. However, while the reticulated pipeline supply is highly valued, in practice it is very unreliable, particularly at certain times of the year (especially in the dry winter season when, traditionally, the stone spout system has been very reliable).

According to experts interviewed and documents analysed, the pipeline water supply system was first introduced in Nepal in I 895. Bir Shamsher Rana (the Prime Minister) installed a piped drinking water supply system in Kathmandu Valley accessed through limited private and public stand posts. The Department of Water Supply and Sewerage (DWSS) was established in 1972 to provide a water and sanitation programme throughout the country. Nepal Water Supply Corporation (NWSC) was responsible for supplying pipeline water, under the DWSS, in the Kathmandu Valley 
until 2008. Kathmandu Upatyaka Khanepani Limited (KUKL) later became the main body responsible for the distribution of drinking water in the Valley. Thus, although stone spouts have been widely used in the Kathmandu Valley since ancient times, after the development of the modern water supply system, stone spouts started to be ignored and further construction ceased. The only time a focus falls on these spouts is when the pipeline malfunctions and alternative sources are needed.

Respondents explained that the Changu-DuwakotJhaukhel Drinking Water Supply System (CDJ DWSS), a large community initiative, has operated since 1998 to provide drinking water to the inhabitants of three Village Development Committee (VDC) areas, Changunarayan, Duwakot and Jhaukhel. Likewise, Changunarayan Brihat Khane Pani Yojana (Changunarayan Multiple Drinking Water Scheme) has also operated since 1995 in the Changunarayan VDC area. Stone spouts were increasingly ignored as modern pipeline water delivery systems have been installed into almost all households. Having water "on tap" at dwellings seemingly negates the need for an additional source of water. For instance, Mohan Shamsher Rana (Prime Minister) built a water tank in 1928 ( 99 years after the last spout built in Nepal) in the Changunarayan VDC Ward Number 9 for the purpose of providing drinking water for the locals. According to respondents, this water tank was the main driver for the deterioration of Sangdaha hiti. A modern tap provided water from the tank adjacent to Sangdaha hiti and consequently people ignored the Sangdaha spout. Many respondents noted that use of the spout had become a superfluous daily activity or was just an extra supply in case of emergencies. This perception resulted in lack of maintenance and the spout dried out around 20 years later. Modern water reticulation was then installed in the area between the two Sangdaha spouts. This exemplifies the way in which the expediency, convenience and assumed reliability of using modern technology has led to failure to maintain complementary alternatives, resulting in a reduction in the resilience of a community to failures in the modern supply system (which are now a common occurrence).

\section{PROPERTY RIGHT ARRANGEMENTS AND THE MANAGEMENT CONTEXT}

The changing state of the stone spout water supply systems can also be seen as a consequence of changes in the institutional structures affecting their management. Common property theory mainly concerns the relationship between property rights and the participation of users in the governance and management of common property resources [I6]. McKean [I7] described a common property regime as a property right arrangement where a group of users share their rights and responsibilities towards a resource. The nature and the degree of ownership over the resources therefore influence user participation in managing common property resources, in this case stone spouts.

Management of common property resources through public participation depends on the nature of ownership and property rights $[\mathrm{I} 6, \mathrm{I} 8]$. There is a lack of a sense of communal ownership of stone spouts, and this adversely affects the management system of traditional water harvesting systems. Historically, spouts were usually operated by the public, and collectively managed through the guthi (a defined social group with spout and related management responsibilities) system. The guthi system was formed by a group of people or members of a family based on caste, patrilineal grouping or by local territorial considerations [19]. Guthi held all rights to access, manage and exclude, although not to alienate, the spouts from the public. However, the guthi systems were disassembled after all the rights regarding managing spouts were handed to the Nepal Guthi Corporation and Department of Archaeology (DoA). All guthi lands were also privatised under the Land Reform Act 1964. Problems have followed in the management of the spouts identified in the study area, especially in the management of Narayan hiti after the privatisation of guthi lands. Previously, the stone spouts of the Kathmandu Valley were managed by either state guthi, the initiator of spouts, or the local people [3]. All community members interviewed during face-to-face interviews and focus group discussions explained that there was a guthi established by the state to look after the stone spouts near the Changunarayan temple area. Three people (called "Dhalapa" in Newari language, meaning water guard) worked together every day and were given I 8 muri (about I, I $52 \mathrm{~kg}$ ) of rice per year grown from land owned by the guthi as a payment for services rendered. They patrolled every day from the water source to each stone spout located in the existing Changunarayan heritage areas. They had responsibilities to guard, maintain and repair the water sources, earthen canals, earthen pots (known as "athah"), as well as any other spout infrastructure or images. The guards also ensured people followed the rules and regulations established for using water from spouts. However, interviews and group discussions show that 
after the enactment of the Land Reform Act of 1964 , spout guthi became inactive in Bhaktapur. Most lands owned by guthi were privatised under this Act, and thereafter there has been no guthi system to provide regular income sources to manage water spouts.

Interviewees commented that, prior to the advent of the water tank and modern piped water, Sangdaha hiti was managed by the local people, but the reduced dependency of the users on the spouts decreased the feeling of ownership and responsibility towards them and significantly contributed to the destruction of Sangdaha hiti. All respondents from the Changunarayan heritage area believe that stone spouts are common property. No individual or group is responsible for looking after them. They saw it as the responsibility of the Nepal Government. However, most planners argued that conservation works should be done by the locals themselves. Despite the lack of local action, the government has not taken full responsibility for maintenance. In summary, when using a common property lens, management funding, property rights, policy, rules, regulations, incentives and lack of communal ownership are identified as the main current institutional aspects affecting the state of both spouts.

Ostrom [20] identified key "design principles" common in institutions successfully managing common property resources. A lack of alignment with these design principles may lead to failure to sustain their common property resources. The weaknesses in the spout management regime for both spouts is highlighted by applying Ostrom's [20] design principles as an analytical framework (Table I). Positively addressing and strengthening key principles, or parts thereof, identified as lacking could help improve the status of these spouts.

As Table I illustrates, the management of the stone spouts falls well short of meeting Ostrom's principles for sustainable management of this heritage. Perhaps the most important of these failures is the removal of rights to organise local institutions to manage the spouts. While there may now be higher level management agency support and expectations that locals will engage in maintenance activities, there may need to be development of a nested and inclusive system that enables this to occur.

\section{CONCLUSION}

This study enhances understanding about sociocultural and institutional norms and values and their role in conserving and sustainably managing traditional water har- vesting and use systems, in this case water supply via stone spouts in Kathmandu Valley, Nepal. Where a spout is of significant spiritual importance, it has been retained in good working condition. However, the research has also shown that modern pipeline systems play a key role in leading to neglect and abandonment of spouts, certainly in the examples reported here. A more complementary approach would ensure the traditional systems are maintained to compensate for the unreliable supply of water from modern systems. However, the alienation of the local community and the transfer of responsibility to external, disconnected bodies, have resulted in no individuals or groups being sufficiently motivated to maintain the historical spout system. Effectively, the centralisation of ownership by the government has destroyed the communally managed common property nature of these technologies, with flow on consequences for their utility, religious, cultural, heritage and tourism values.

\section{CASE STUDY QUESTIONS}

I. What roles do community held sociocultural beliefs have in efforts to sustainably manage traditional forms of infrastructure, including water supply systems? Are these beliefs given sufficient weight in decision-making processes?

2. What barriers and problems are faced in the ongoing management of traditional forms of infrastructure, including water supply systems?

3. What is the nature of the relationship between governmental and non-governmental organisations and social institutions regarding management of traditional water supply structures (e.g., stone spouts)? How might integration of institutional interests be encouraged?

4. How important is the property management structure in determining resource management decisions about traditional water supply systems? Can Ostrom's "design principles" be applied to similar resource management issues?

5. Please describe a specific case in which a different strategy was used for water supply heritage preservation. How effective was this strategy? Where was it ineffective? If there are no strategies how might one be designed and what might it contain? 
TABLE 1. Evaluation of spout management regimes against Ostrom's [20] design principles

\begin{tabular}{ll}
\hline Design principles & Weakness of spout management regime based on design principles \\
\hline Clear boundaries & - No clear definition of users \\
& - Management institutions are not interested in maintenance \\
Congruent rules & - Rituals, sociocultural norms and values are gradually breaking down \\
Collective choice arrangements & - Lack of communal ownership and responsibility over spouts \\
Monitoring & - Absence of monitoring arrangements \\
Graduated sanctions & - The community has no legal authority to impose punishment for encroaching on plat- \\
& - forms, stealing artistic or religious features and damaging spout infrastructure \\
Conflict resolution & - No conflict resolution mechanisms \\
Rights to organise institutions & national level government and, in fact, were handed to the Nepal Guthi Corporation and \\
& Department of Archaeology \\
Nested units & Multiple levels of institutional arrangements for managing spouts do not exist
\end{tabular}

6. Are there legal provisions concerning the control of development activities that influence the conservation and management of traditional water supply structures (e.g., stone spouts)? If there are, then are they effective in sustaining this heritage and, if not, then why not?

\section{AUTHOR CONTRIBUTIONS}

Study conception and design; final approval of the version to be published-KFDH, HGR and MT. Writing original draft; acquisition, analysis and interpretation of data-MT. Supervision and critical revision-KFDH and HGR.

\section{ACKNOWLEDGEMENTS}

We are grateful to the anonymous reviewers for their feedback.

\section{FUNDING}

We are grateful to Lincoln University, New Zealand, for research funding support.

\section{COMPETING INTERESTS}

The authors have declared that no competing interests exist.

\section{REFERENCES}

I. Collins R, Kristensen P, Thyssen N. Water Resources across Europe-Confronting Water Scarcity and Drought. Copenhagen, Denmark: Office for Official Publications of the European Communities (OPOCE); 2009.
2. UNU-INWEH. Using Traditional Approaches for Water Management in Drylands. France: United Nations University International Network on Water, Environment and Health; 2009.

3. Tripathi M. A comparative evaluation of stone spout management systems in heritage and non-heritage areas of Kathmandu Valley, Nepal. Unpublished doctoral thesis, Lincoln, New Zealand: Lincoln University; 2016.

4. Manandhar A. Sithi Nakha: the Newar environment festival. NGO Forum for Urban Water and Sanitation. 20 I I. Available: http://www.ngoforum.net/index.php?option=co $\mathrm{m}_{-}$content\&task=view\&id= 1 I 305 . Accessed 2 February 2016.

5. UN-Habitat. Water Movement in Patan: With Reference to Traditional Stone Spouts in Nepal. Kathmandu, Nepal: United Nations Human Settlements Programme: United Nations Information Centre; 2008.

6. Zafar A. Seeing Traditional Technologies in a New Light. 2009. Available: http://unesdoc.unesco.org/images/00 1 8/ 001817/181799E.pdf. Retrieved 9 September 2017.

7. Khaniya G. Traditional Water Management Practices: A Case Study of Bhaktapur City. 2005. Available: http://www.jvsnwp.org.np/sites/default/files/Number\%20\%2028.pdf

8. Lukinbeal C. Traditional Infrastructure, Modern Flows: Cultural Politics of Development in the Kathmandu Valley, Nepal. n.d. Available: http://apcgweb.org/sites/default/files/ editor_uploads/files/pacificaf I 4.pdf.

9. NGO Forum. Delivering Water to the Poor. A Case Study of the Kathmandu Valley Urban Water Supply Reforms with a Special Focus on the Melamchi Project. Kathmandu, Nepal: NGO Forum for Urban Water and Sanitation; 2005. Available: http://www.ircwash.org/sites/default/files/822-NEKAos- 88 86.pdf.

ı. NGO Forum. Traditional Stonespouts. 20 Iо. Available: http://www.ngoforum.net/index.php?option=co $\mathrm{m}_{-}$content\&task $=$view\&id $=9800 \&$ Itemid $=78$. Retrieved 2 February 2016. 
I I. Becker-Ritterspach R. Dhunge-dharas in the Kathmandu valley: an outline of their architectural development. Ancient Nepal. i 990: i i 6-i i 8.

I 2. Spodek, J. C. Ancient newari water-supply systems in Nepal's Kathmandu Valley. APT Bull. 2002;33(2/3):65-69.

13. Pathak DR, Hiratsuka A, Yamashiki Y. Influence of anthropogenic activities and seasonal variation on groundwater quality of Kathmandu using multivariate statistical analysis. Assessment of Water Quality under Changing Climate Conditions, Proceedings of Symposium $\mathrm{H}_{0} 4$ Held during IUGG20 I I. Vol. 348. Melbourne: IAHS Red Book; 20 I I. pp. $67-72$.

I4. Tripathi M, Hughey KFD, Rennie HG. The State of Traditional Stone Spouts in Relation to Their Use and Management in Kathmandu Valley, Nepal. In press.

I 5. Government of Nepal. Village Profile of Changunnarayan Village Development Committee. Changunnarayan: Changunarayan VDC; $201 \mathrm{I}$.

16. Schlager E, Ostrom E. Property-rights regimes and natural resources: a conceptual analysis. Land Econ. 1992;68: 249-262.
17. McKean MA. Common property: what is it, what is it good for, and what makes it work. In: Gibson CC, McKean MA, Ostrom E, editors. People and Forests: Communities, Institutions, and Governance. Cambridge, MA: MIT Press; 2000. pp. 27-55.

18. Agrawal A. Common property institutions and sustainable governance of resources. World Dev. 2001;29(10): I $649-1672$.

19. Pradhananga N, Shrestha KK, Dee J. Sustaining indigenous heritage: learning from the Guthi System in Nepal. Presented to the New Zealand Geographical Society Conference 20 I o, 5-8 July 20 го. Christchurch, New Zealand: 20 I 0 . Available: https://www.a cademia.edu/ I052649/Sustaining_Indigenous_Heritage_Learnin g_from_the_Guthi_System_in_Nepal

20. Ostrom E. Governing the Commons: The Evolution of Institutions for Collective Action. Cambridge, UK: Cambridge University Press; 1990. 